\title{
Palha de Sorgo Associada ao Herbicida imazamox no Controle de Plantas daninhas na Cultura da Soja em Sucessão
}

\author{
Sorghum Mulch Combined with Imazamox for Weed Control in Soybeans Planted in Succession
}

\author{
CORREIA, N.M. ${ }^{2}$, SOUZA, I.F. ${ }^{3}$ e KLINK, U.P. ${ }^{4}$
}

\begin{abstract}
RESUMO - Os resíduos vegetais de uma cultura de cobertura de outono/inverno podem interferir na infestação das plantas daninhas das culturas de verão subseqüentes. Dessa forma, com o objetivo de avaliar o efeito da palha de híbridos de sorgo (Sorghum bicolor), associada ao uso do herbicida imazamox, no controle de plantas daninhas na cultura da soja (Glycine max), cv. 'Conquista', em sucessão, foi conduzido no ano agrícola 2000/2001 um experimento em Uberlândia-MG. Foram utilizados quatro tipos de cobertura: três provenientes de resíduos culturais de híbridos de sorgo (Sara, DKB 860 e Ambar) e uma sem restos vegetais (anteriormente sob pousio). Aos 24 dias após aplicação do herbicida, o controle das espécies Leonotis nepetifolia, Alternanthera tenella, Amaranthus hibridus, A. retroflexus, A. spinosus, Ipomoea grandifolia, Commelina benghalensis e Nicandra physaloides foi mais eficaz nas palhas dos híbridos Sara e Ambar, na ausência de imazamox, com porcentagens de controle de 40 e $41 \%$, respectivamente. Quando associada a $15 \mathrm{~g} \mathrm{ha}^{-1} \mathrm{de}$ imazamox, a palha do Ambar resultou em melhor controle dessas espécies de plantas daninhas, com controle de $76 \%$; e a $30 \mathrm{~g} \mathrm{ha}^{-1}$ a palha do DKB 860 foi a mais eficaz, promovendo $85 \%$ de controle. Sem cobertura do solo, com $30 \mathrm{~g} \mathrm{ha}^{-1}$ de imazamox obteve-se controle de $62,5 \%$, e $47,5 \%$ com metade da dosagem. Os resultados indicaram variabilidade de controle em relação ao híbrido de sorgo estudado e a possibilidade de redução de dosagens do herbicida imazamox quando associado aos resíduos vegetais de sorgo.
\end{abstract}

Palavras-chave: Sorghum bicolor, Glycine max, alelopatia, semeadura direta.

\begin{abstract}
Plant residues of a fall/winter coverage crop can influence weed infestation of the subsequent summer crops. This research was carried out to evaluate the effects of mulch from several sorghum (Sorghum bicolor) hybrids plus the herbicide imazamox on the control of the subsequent weed infestation of soybean crop (Glycine max $c v$. 'Conquista'). The experiment was carried out in the 2000/2001 crop year in Uberlândia, MG. Four types of mulch were used, three from sorghum hybrid residues (Sara, DKB 860 and Ambar) and one without residues (no previous winter crop). Twenty-four days after the application of imazamox, the control of the species Leonotis nepetifolia, Aternanthera tenella, Amaranthus hibridus, A. retroflexus, A. spinosus, Ipomoea grandifolia, Commelina benghalensis, and Nicandra physaloides was more effective with the use of Sara or Ambar mulch without the herbicide, with 40 and $41 \%$ of control, respectively. When associated to $15 \mathrm{~g} \mathrm{ha}^{-1}$ of imazamox, Ambar mulch resulted in better efficiency, with 76\% of control. DKB 860 combined with $30 \mathrm{~g} \mathrm{ha}^{-1}$ of imazamox was the most efficient treatment, providing $85 \%$ of weed control. Without soil coverage, $62.5 \%$ of control was achieved with $30 \mathrm{~g} \mathrm{ha}^{-1}$ of imazamox and $47.5 \%$ with $15 \mathrm{~g} \mathrm{ha}^{-1}$. The results indicated wide control variability in relation to the sorghum hybrid used and possibility of imazamox dose reduction when associated to sorghum residues.
\end{abstract}

Key words: Sorghum bicolor, Glycine max, allelopathy, no-till system.

\section{Recebido para publicação em 9.9.2003 e na forma revisada em 5.9.2005.}

Eng.-Agr. D.S., Dep. de Produção Vegetal, Universidade Estadual Paulista, Campus de Jaboticabal, 14870-000 Jaboticabal-SP, $<$ correianm@yahoo.com.br>. ${ }^{3}$ Eng.-Agr. Ph.D., professor do Departamento de Agricultura, Universidade Federal de Lavras, Caixa Postal, 37, 37200-000 Lavras-MG, <itamarfs@ufla.br>. ${ }^{4}$ Eng.-Agr. M.S., Gerente de Pesquisa, Monsanto Sementes S.A., <urubatan.p.klink@monsanto.com>.

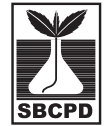




\section{INTRODUÇÃO}

O sorgo (Sorghum bicolor) consiste numa excelente alternativa como cultura de outono/ inverno, produzindo cobertura apropriada para o estabelecimento do sistema de semeadura direta no cerrado, pois se caracteriza por resistir melhor às condições de deficiência hídrica, com elevada capacidade de aproveitamento da água e conversão em biomassa seca. Também se deve levar em consideração que a palha de sorgo apresenta alta relação $\mathrm{C} / \mathrm{N}$ e, conseqüentemente, maior persistência no solo. Além das características relacionadas, o sorgo possibilita rotação e sucessão a outras culturas, destacando-se a cultura da soja na região Central do Brasil.

Outro aspecto a ser mencionado é que as plantas de sorgo possuem a capacidade de exsudar aleloquímicos através dos pêlos radiculares, compostos estes que também são encontrados nas sementes, raízes, colmos e folhas em quantidades variáveis (Peixoto \& Souza, 2002), interferindo no manejo das plantas cultivadas (Peixoto \& Souza, 2002; Cheema $\&$ Khaliq, 2000; Roth et al., 2000) e daninhas (Einhellig \& Rasmussen, 1989; Hoffman et al., 1996a, b; Cheema \& Khaliq, 2000; Peixoto \& Souza, 2002; Mateus et al., 2004; Trezzi \& Vidal et al., 2004).

No entanto, a inibição da palha de sorgo no controle das plantas daninhas não pode ser atribuída unicamente à alelopatia, visto que os resíduos vegetais mantidos na superficie do solo alteram a umidade, luminosidade e temperatura do solo, principais elementos no controle da dormência e germinação de sementes. A cobertura, também, pode prejudicar as plântulas em desenvolvimento, devido à barreira física, causando o estiolamento das plantas e tornando-as suscetiveis aos danos mecânicos. Finalmente, ela pode favorecer o desenvolvimento de insetos e fungos, que se alimentam ou se hospedam nas sementes e na parte aérea das plantas daninhas. Esses efeitos podem ocorrer de forma isolada ou através da interação entre eles.

Diversos estudos têm sido conduzidos visando o manejo dos resíduos vegetais de sorgo no controle de plantas daninhas e, na maior parte dos trabalhos, os resultados indicam uma variabilidade de resposta em relação ao genótipo de sorgo estudado. Quando determinada a potencialidade alelopática de um genótipo, os resultados poderão auxiliar na escolha do genótipo mais adequado para a sucessão sorgo (inverno) e a cultura subseqüente (verão). Esse tipo de manejo pode contribuir para a redução do uso de herbicidas, atenuando o impacto ambiental provocado por esses produtos e o custo de produção da cultura em sucessão.

O presente trabalho teve como objetivo avaliar, no campo, o efeito da palha de híbridos de sorgo cultivados no outono/inverno, como cobertura morta, associada ao uso do herbicida imazamox no controle de plantas daninhas na cultura da soja em sucessão, sob semeadura direta, no verão.

\section{MATERIAL E MÉTODOS}

O experimento foi conduzido de março de 2000 a março de 2001, em campo, na Fazenda Três Marcos, localizada em Uberlândia-MG, a uma altitude de aproximadamente 872 metros, latitude de $18^{\circ} 55^{\prime}$ 'S e longitude de $48^{\circ} 17^{\prime} \mathrm{W}$. Segundo a classificação de Köeppen, o clima da região é do tipo Aw. O solo da área experimental é representativo da região, sendo classificado como Latossolo Vermelho-Amarelo, textura argilosa, originalmente sob cerrado.

Antecedendo a semeadura do sorgo, realizou-se a dessecação das plantas daninhas da área experimental com 1,44 $\mathrm{kg} \mathrm{ha}^{-1} \mathrm{de}$ ghyphosate (equivalente ácido). Os híbridos de sorgo (Sara, DKB 860 e Ambar) foram semeados em faixas, no dia 20 de março de 2000, sob palha de soja e de plantas daninhas, em sistema de semeadura direta. Após a semeadura, foi aplicada a mistura dos herbicidas atrazine $\left(1,5 \mathrm{~kg} \mathrm{ha}^{-1}\right)$ e paraquat $\left(0,3 \mathrm{~kg} \mathrm{ha}^{-1}\right)$. Os genótipos de sorgo foram adubados na linha de semeadura $\left(255 \mathrm{~kg} \mathrm{ha}^{-1}\right.$ do formulado 8-30-15) e em cobertura (43 $\mathrm{kg} \mathrm{ha}^{-1}$ de nitrogênio), conforme análise de solo (Tabela 1) e necessidade nutricional da cultura.

As faixas foram constituídas por seis linhas espaçadas de 0,5 m e com $60 \mathrm{~m}$ de comprimento, na densidade de 12 plantas por metro linear, perfazendo uma população de 240 mil plantas ha ${ }^{-1}$. Foi destinada para testemunha uma faixa com mesma dimensão (3 $\mathrm{m}$ de largura por $60 \mathrm{~m}$ de comprimento), 
sem cultura de outono/inverno, denominada de pousio, que também foi tratada com o herbicida glyphosate, na mesma época e dosagem utilizada na área de sorgo.

No estádio de enchimento de grãos, mediu-se a altura $(\mathrm{cm})$ das plantas de sorgo, considerando a distância entre a superficie do solo e a extremidade da panícula. Foram amostradas, aleatoriamente, 24 plantas por faixa.

Foi determinada, cinco dias antes da colheita dos grãos, a matéria seca da parte aérea ( $\left.\mathrm{kg} \mathrm{ha}^{-1}\right)$ por híbrido de sorgo. Em cada faixa, foram delimitados quatro pontos de amostragem, escolhidos aleatoriamente, com 0,5 m²; em cada ponto coletaram-se 12 plantas, as quais tiveram as paniculas eliminadas. Em seguida, as plantas foram fragmentadas e levadas para secar a $62{ }^{\circ} \mathrm{C}$ em estufa de circulação forçada de ar, até atingirem massa constante.

Os grãos foram colhidos 156 dias após a emergência das plântulas, com colhedora automotriz, por faixa, separadamente. Após a colheita as plantas foram trituradas, utilizando-se um cortador de palha do tipo triton, e deixadas sobre as faixas.

Trinta e seis dias após a trituração das plantas, fez-se a dessecação química da rebrota de sorgo, quando estas se encontravam com $20 \mathrm{~cm}$ de altura. As plantas daninhas presentes na faixa do pousio também foram dessecadas. Foi utilizado o herbicida glyphosate na dosagem de $1,8 \mathrm{~kg} \mathrm{ha}^{-1}$ de equivalente ácido. $\mathrm{Na}$ faixa do pousio, a palha remanescente sobre o solo, oriunda das plantas daninhas, foi rastelada, a fim de se ter no momento da semeadura da soja o solo nu, sem nenhum tipo de resíduo vegetal.

Antecedendo a semeadura da soja, foi realizada análise de solo para cada faixa de sorgo e para aquela mantida em pousio. Os resultados podem ser observados na Tabela 2 . Com base nas análises de solo e na necessidade nutricional da soja, fez-se a recomendação de adubação, que foi a mesma para todas as faixas. Foram aplicados $329 \mathrm{~kg} \mathrm{ha}^{-1}$ do formulado 02-20-20 no sulco de semeadura.

A soja foi semeada sobre as faixas de sorgo e pousio um mês após a dessecação da rebrota das plantas, no dia $1^{\circ}$ de novembro de 2001, em sistema de semeadura direta, numa profundidade de $5 \mathrm{~cm}$, com 0,5 m de distância entre as linhas e 20 plantas por metro linear, perfazendo uma população de 400 mil plantas $\mathrm{ha}^{-1}$. As sementes foram tratadas com carboxin $\left(1,5 \mathrm{~g} \mathrm{~kg}^{-1}\right.$ de sementes) e inoculadas com $7,5 \mathrm{~g} \mathrm{~kg}^{-1}$ de sementes do inoculante da marca Leiva. A variedade utilizada foi a Conquista.

Tabela 1 - Resultados da análise de solo ${ }^{1 /}$ realizada antes da semeadura do sorgo. Uberlândia-MG, 2000/2001

\begin{tabular}{|c|c|c|c|c|c|c|c|}
\hline \multirow{2}{*}{$\begin{array}{c}\text { pH água } \\
(1: 2,5)\end{array}$} & $\mathrm{P}$ & $\mathrm{K}$ & $\mathrm{Ca}$ & $\mathrm{Mg}$ & $\mathrm{Al}$ & $\mathrm{V}$ & $\mathrm{MO}$ \\
\cline { 2 - 9 } & \multicolumn{2}{|c|}{$\mathrm{mg} \mathrm{dm}^{-3}$} & \multicolumn{3}{|c|}{$\mathrm{cmol}_{\mathrm{c}} \mathrm{dm}^{-3}$} & $\%$ & $\mathrm{dag} \mathrm{kg}^{-1}$ \\
\hline 6,00 & 9,5 & 82,0 & 4,8 & 1,2 & - & 66,7 & 3,3 \\
\hline
\end{tabular}

${ }^{1 /}$ LAGRO = Laboratório Agronômico SC Ltda. Campinas-SP.

Tabela 2 - Resultados das análises de solo ${ }^{\frac{1}{-}}$ realizadas antes da semeadura da soja. Uberlândia-MG, 2000/2001

\begin{tabular}{|l|c|c|c|c|c|c|c|c|c|}
\hline \multirow{2}{*}{ Parcela } & \multirow{2}{*}{$\begin{array}{c}\mathrm{pH} \text { água } \\
(1: 2,5)\end{array}$} & \multicolumn{2}{|c|}{$\mathrm{P}$} & $\mathrm{K}$ & $\mathrm{Ca}$ & $\mathrm{Mg}$ & $\mathrm{Al}$ & $\mathrm{V}$ & $\mathrm{MO}$ \\
\cline { 3 - 11 } & \multicolumn{2}{|c|}{$\mathrm{mg} \mathrm{dm}^{-3}$} & \multicolumn{3}{|c|}{$\mathrm{cmol}_{\mathrm{c}} \mathrm{dm}^{-3}$} & & $\%$ & $\mathrm{dag} \mathrm{kg}^{-1}$ \\
\hline Sara & 6,3 & 6,0 & 97,0 & 3,3 & 1,1 & - & 64,1 & 3,3 \\
\hline DKB 860 & 6,3 & 9,0 & 72,0 & 3,3 & 1,9 & 0,1 & 70,1 & 3,6 \\
\hline Ambar & 6,6 & 7,0 & 58,0 & 3,7 & 1,8 & - & 76,9 & 3,1 \\
\hline Pousio & 5,9 & 8,0 & 90,0 & 3,5 & 1,0 & 0,1 & 69,3 & 3,5 \\
\hline
\end{tabular}

(1// Laboratório de Análises de Solo do Departamento de Ciência do Solo/UFLA. Lavras-MG. 
As faixas referentes aos residuos vegetais dos híbridos de sorgo e do pousio foram divididas em parcelas com $3 \mathrm{~m}$ de largura e $15 \mathrm{~m}$ de comprimento. Dentro de cada parcela demarcaram-se as subparcelas correspondentes às dosagens de imazamox $\left(0,15\right.$ e $\left.30 \mathrm{~g} \mathrm{ha}^{-1}\right)$. As subparcelas foram constituidas por seis linhas de soja com $5 \mathrm{~m}$ de comprimento, sendo quatro linhas centrais de $4 \mathrm{~m}$ de comprimento como área útil, totalizando $8 \mathrm{~m}^{2}$.

O herbicida imazamox foi aplicado em pósemergência precoce das plantas daninhas, quando estas se encontravam com dois pares de folhas definitivas e as plantas de soja estavam com o segundo trifólio totalmente expandido. Foi utilizado pulverizador costal, à pressão constante de $2,8 \mathrm{~kg} \mathrm{~cm}^{-2}$, munido de barra com quatro bicos de jato plano ("leque") uniforme 8002, espaçados de 0,5 m e com consumo de calda equivalente a $200 \mathrm{~L} \mathrm{ha}^{-1}$.

Aos 10, 24 e 54 dias após aplicação do imazamox (DAA), foram realizadas avaliações visuais de controle das plantas daninhas, atribuindo-se notas em porcentagem. Devido ao menor controle observado no tratamento do pousio na dosagem de $0 \mathrm{~g} \mathrm{ha}^{-1}$ de imazamox, este foi considerado como testemunha, recebendo a nota $0 \%$; por comparação, atribuiu-se a nota dos demais tratamentos, em que 100\% representaria a ausência total de plantas daninhas. A cada unidade experimental foi atribuída a nota média de dois avaliadores.

No fim do ciclo da soja, foi coletada a matéria fresca da parte aérea das plantas daninhas, numa área de 0,25 $\mathrm{m}^{2}$ escolhida aleatoriamente dentro da área útil da subparcela. O material foi acondicionado em sacos de papel e levado à estufa com circulação forçada de ar a $62{ }^{\circ} \mathrm{C}$, até atingir massa constante, e pesado em seguida.

O delineamento experimental utilizado foi o de blocos ao acaso com quatro repetições, em esquema de parcela subdividida. Foram mantidos quatro tipos de cobertura do solo na parcela: três provenientes de resíduos culturais de híbridos de sorgo (Sara, DKB 860 e Ambar) e uma sem restos vegetais (anteriormente sob pousio), além de três dosagens de imazamox na subparcela: sem herbicida $\left(0 \mathrm{~g} \mathrm{ha}^{-1}\right)$, metade da dosagem recomendada
(15 $\left.\mathrm{g} \mathrm{ha}^{-1}\right)$ e dosagem recomendada (30 $\left.\mathrm{g} \mathrm{ha}^{-1}\right)$. Os resultados foram submetidos ao teste $F$, para análise de variância. Os efeitos das palhas e do herbicida imazamox foram comparados pelo teste de Tukey em nivel de 5\% de probabilidade.

\section{RESULTADOS E DISCUSSÃO}

\section{Dinâmica das espécies de plantas daninhas}

As principais espécies de plantas daninhas observadas na área experimental foram: Leonotis nepetifolia, Alternanthera tenella, Amaranthus hibridus, A. retroflexus, A. spinosus, Ipomoea grandifolia, Commelina benghalensis e Nicandra physaloides. Na Tabela 3 está representada a freqüência de cada espécie nos diferentes tipos de cobertura.

A esse respeito, observou-se que Alternanthera tenella distribuiu-se principalmente sob solo sem residuos vegetais e sob palha do DKB 860. Não houve infestação desta espécie sob palha do Sara. Quanto às espécies Amaranthus spp., verificou-se maior freqüência sob os resíduos dos híbridos DKB 860 e Ambar. A espécie Ipomoea grandifolia distribuiu-se sob solo sem cobertura e sob palha do Sara, com 32 e 34\% de ocorrência, respectivamente. Ao observar o comportamento de distribuição da espécie Leonotis nepetifolia, comprovou-se maior freqüência sob palha do híbrido Sara, com 38\% de toda a ocorrência desta espécie na área experimental. Nicandra physaloides distribuiu-se em todos os tipos de cobertura, com oscilação de ocorrência entre 17 e $35 \%$.

Tabela 3 - Freqüência (\%) por espécie de planta daninha sob solo sem cobertura e sob palhas de três híbridos de sorgo no momento da colheita dos grãos de soja, cultivada em sucessão ao sorgo. Uberlândia-MG, 2000/2001

\begin{tabular}{|c|c|c|c|c|}
\hline \multirow{2}{*}{ Espécie } & \multicolumn{3}{|c|}{ Palha de híbridos de sorgo } & \multirow{2}{*}{$\begin{array}{l}\text { Solo sem } \\
\text { cobertura }\end{array}$} \\
\hline & Sara & DKB 860 & Ambar & \\
\hline Alternanthera tenella & 0 & 47 & 13,0 & 40,0 \\
\hline Amaranthus spp. & 19 & 38 & 34,5 & 8,5 \\
\hline Commelina benghalensis & 17 & 12 & 18,0 & 53,0 \\
\hline Ipomoea grandifolia & 34 & 10 & 24,0 & 32,0 \\
\hline Leonotis nepetifolia & 38 & 22 & 26,0 & 14,0 \\
\hline Nicandra physaloides & 33 & 25 & 25,0 & 17,0 \\
\hline
\end{tabular}


Para Commelina benghalensis, constatouse maior freqüência sob solo sem resíduos vegetais, com $53 \%$ de toda a ocorrência desta espécie na área experimental, enquanto sob palha do DKB 860 observou-se menor distribuição da espécie, com o valor de 12\%. Esta espécie assume atualmente grande importância em áreas de semeadura direta no cerrado e, também, em áreas de cafeicultura. Comprovado o efeito inibitório da cobertura morta de sorgo sobre $C$. benghalensis, o produtor passa a ter uma nova alternativa de manejo, por meio da associação de resíduos vegetais de sorgo e o uso de herbicidas específicos, porém em menores dosagens e com resultados mais satisfatórios.

Deve-se considerar que a distribuição das espécies de plantas daninhas no momento da semeadura do sorgo era uniforme em toda a área experimental; contudo, observou-se freqüência desuniforme no momento da colheita dos grãos de soja, o que pode ser explicado pela diversificação das espécies que compunham o banco de sementes de cada parcela, ou por uma possivel "seleção" das plantas daninhas pelo tipo de palha.

\section{Controle das plantas daninhas}

Pode ser observado na Tabela 4, aos 10 DAA, que não houve diferença significativa entre as dosagens de imazamox na palha do híbrido Sara. No entanto, nos demais tipos de cobertura a aplicação do herbicida, seja a metade ou a dosagem recomendada, diferiu significativamente do tratamento sem herbicida.

Foi constatado efeito significativo das coberturas para cada dosagem do herbicida, indicando que as dosagens apresentaram controle diferenciado em função dos resíduos vegetais. Sem a aplicação do herbicida, aos 10 DAA, verificou-se melhor controle das plantas daninhas sob palha do híbrido Ambar, não diferindo do Sara. Quando se realizou a aplicação do herbicida mesmo na metade da dosagem, novamente a palha do Ambar resultou em maior porcentagem de controle, diferindo daquela dos demais tipos de cobertura.

$\mathrm{Na}$ avaliação realizada aos 24 DAA, mais uma vez não foi observada diferença significativa entre as dosagens de imazamox na palha do Sara. A aplicação do herbicida, nas duas dosagens estudadas, resultou em melhor controle sob solo sem cobertura e sob palha do Ambar. Na palha do híbrido DKB 860 a dosagem recomendada foi superior à meia dosagem.

Sem a aplicação de imazamox, nas palhas dos híbridos Sara e Ambar houve melhor controle, porém com baixos valores. A aplicação da metade da dosagem de imazamox proporcionou aumento nas porcentagens de controle para todas as coberturas, principalmente para o DKB 860, com 55\% de acréscimo. Entretanto, a palha do Ambar, mesmo apresentando aumento inferior de $35 \%$, foi a mais eficaz no controle das plantas daninhas nesta dosagem. Quando se realizou a aplicação da dosagem recomendada, a palha do DKB 860 proporcionou melhor resultado, não diferindo significativamente da palha do híbrido Ambar.

Em relação à última época de avaliação, aos 54 DAA, não houve diferença estatística entre a metade e a dosagem recomendada de imazamox para as palhas de sorgo, independentemente do híbrido, sendo superiores aos tratamentos sem herbicida. No solo sem resíduos vegetais, observou-se melhor controle apenas com a aplicação da dosagem recomendada de imazamox.

Foi verificado, também, que houve efeito significativo das coberturas para cada dosagem, ou seja, cada dosagem resultou em um controle diferenciado de acordo com a cobertura. As coberturas que não foram submetidas à aplicação de imazamox não diferiram entre si. O mesmo ocorreu com aquelas que receberam a dosagem recomendada do herbicida. No entanto, utilizando-se apenas metade da dosagem, houve controle eficiente nas palhas dos híbridos DKB 860 e Ambar.

Para matéria seca das plantas daninhas, não se observou diferença estatística entre a metade e a dosagem recomendada do herbicida para as palhas dos híbridos Sara e Ambar. Foi constatada redução de $52 \%$ para o Sara e $75 \%$ para o Ambar no acúmulo de massa das plantas daninhas, comparadas aos seus respectivos tratamentos sem herbicida. No solo sem cobertura e na palha do DKB 860, as menores médias foram obtidas com a aplicação da dosagem recomendada, com reduções de 83 e $96 \%$, respectivamente. Contudo, na palha do híbrido DKB 860 com apenas metade da

Planta Daninha, Viçosa-MG, v. 23, n. 3, p. 483-489, 2005 
Tabela 4 - Acúmulo de matéria seca $\left(\mathrm{g} \mathrm{m}^{-2}\right)$ e porcentagem de controle de plantas daninhas aos 10, 24 e 54 dias após aplicação (DAA) de três dosagens do herbicida imazamox sobre quatro tipos de cobertura do solo (três provenientes de palha de híbridos de sorgo e uma sem cobertura do solo), na cultura da soja em sucessão ao sorgo. Uberlândia-MG, 2000/2001

\begin{tabular}{|c|c|c|c|c|c|}
\hline \multirow{2}{*}{ Avaliação } & \multirow{2}{*}{$\begin{array}{c}\text { Dosagem } \\
\left(\mathrm{g} \mathrm{ha}^{-1}\right)\end{array}$} & \multicolumn{3}{|c|}{ Palha de híbridos de sorgo } & \multirow{2}{*}{ Sem cobertura do solo } \\
\hline & & Sara & DKB 860 & Ambar & \\
\hline \multirow{3}{*}{10 DAA } & Zero & 35,00 a $\mathrm{A}$ & $10,00 \mathrm{~b} \mathrm{~B}$ & $53,75 \mathrm{~b} \mathrm{~A}$ & $0,00 \mathrm{~b} \mathrm{~B}$ \\
\hline & 15 & 37,50 a B & $55,00 \mathrm{a} \mathrm{B}$ & 88,75 a A & 45,63 a B \\
\hline & 30 & $55,00 \mathrm{a} \mathrm{B}$ & 67,50 a $\mathrm{AB}$ & 91,25 a A & $57,50 \mathrm{a} \mathrm{B}$ \\
\hline \multirow{3}{*}{24 DAA } & Zero & 40,00 a $\mathrm{A}$ & 7,50 c B & $41,13 \mathrm{~b} \mathrm{~A}$ & $0,00 \mathrm{~b} \mathrm{~B}$ \\
\hline & 15 & 60,00 a $\mathrm{AB}$ & $62,50 \mathrm{~b} \mathrm{AB}$ & 76,25 a A & 47,50 a B \\
\hline & 30 & 57,50 a C & 85,00 a A & $82,50 \mathrm{a} \mathrm{AB}$ & 62,50 a BC \\
\hline \multirow{3}{*}{54 DAA } & Zero & $0,00 \mathrm{~b} \mathrm{~A}$ & $0,00 \mathrm{~b} \mathrm{~A}$ & $0,00 \mathrm{~b} \mathrm{~A}$ & $0,00 \mathrm{c} \mathrm{A}$ \\
\hline & 15 & $53,75 \mathrm{a} \mathrm{AB}$ & 72,50 a A & 77,50 a A & $37,50 \mathrm{~b} \mathrm{~B}$ \\
\hline & 30 & 73,75 a A & 90,75 a A & 86,25 a A & 87,50 a A \\
\hline \multirow{3}{*}{ Matéria seca } & Zero & 283,49 b A & 524,79 с B & $380,09 \mathrm{~b} \mathrm{AB}$ & 475,05 c B \\
\hline & 15 & 135,19 a A & $119,23 \mathrm{~b} \mathrm{~A}$ & 88,11 a A & $338,93 \mathrm{~b} \mathrm{~B}$ \\
\hline & 30 & 136,14 a B & 21,66 a A & $104,51 \mathrm{a} \mathrm{B}$ & 80,37 a B \\
\hline
\end{tabular}

Médias seguidas pelas mesmas letras, minúsculas nas colunas e maiúsculas nas linhas, não diferem significativamente entre si pelo teste de Tukey a $5 \%$ de probabilidade.

dosagem do imazamox, obteve-se redução de $77 \%$ na matéria seca das plantas daninhas.

Ainda referente à matéria seca de plantas daninhas, verificou-se que sem herbicida a palha do DKB 860 apresentou maior média, porém esta foi a que proporcionou menor acúmulo de biomassa seca com a aplicação de imazamox.

Neste estudo, constatou-se que o Ambar apresentou maior altura de planta $(147,67 \mathrm{~cm})$, seguido do DKB 860 (132,96 cm) e Sara $(117,67 \mathrm{~cm})$. Ben-Hammouda et al. (1995a) afirmaram que, com base numa relação parte aérea/raiz de 7:1 e no conhecimento de que o colmo apresenta a maior proporção de biomassa aérea, o potencial alelopático de resíduos de sorgo pode ser atribuido em grande parte ao colmo da planta, o que poderia justificar o desempenho alelopático das palhas do Ambar e DKB 860. Esses autores também relataram que os extratos do colmo mostraram maior atividade inibitória em relação às demais partes da planta de sorgo, inibindo o crescimento da radícula de plântulas de trigo em $75 \%$.

Quanto à produção de matéria seca, o híbrido Ambar acumulou $5.430 \mathrm{~kg} \mathrm{ha}^{-1}$; o DKB $860,5.425 \mathrm{~kg} \mathrm{ha}^{-1}$; e o Sara, $5.045 \mathrm{~kg} \mathrm{ha}^{-1}$, mostrando que a quantidade de resíduos vegetais mantidos na superficie do solo foi aproximadamente a mesma para os três híbridos. Como não houve diferença expressiva na quantidade de palha produzida, a variabilidade de controle de plantas daninhas observada entre os híbridos pode estar associada à concentração e composição de substâncias alelopáticas nos tecidos vegetais de cada híbrido. Outros autores também comprovaram a variabilidade no potencial alelopático de híbridos de sorgo (Ben-Hammouda et al., 1995a, b; Santos, 1996; Nimbal et al., 1996; Weston et al., 1997; Barbosa et al., 1998).

Com base nos resultados obtidos, pode-se inferir que a palha de sorgo potencializou o efeito deletério do herbicida sobre as plantas daninhas, principalmente os resíduos do híbrido Ambar. Nesse caso, com metade da dosagem de imazamox (15 $\left.\mathrm{g} \mathrm{ha}^{-1}\right)$ obteve-se controle satisfatório, similar à dosagem recomendada (30 $\left.\mathrm{g} \mathrm{ha}^{-1}\right)$. A cobertura morta na superfície do solo melhora a eficiência dos herbicidas, pois a plântula, ao romper a palha, fica enfraquecida, facilitando o seu controle pelo herbicida. Além do efeito físico, fitotoxinas presentes na palha podem inibir a emergência e o desenvolvimento da plântula, porém não promovem a sua mortalidade, o que é favorecido em associação ao controle químico. 


\section{LITERATURA CITADA}

BARBOSA, L. C. A. et al. Preparation and phytotoxicity of sorgoleone analogues. Química Nova, v. 24, n. 6, p. 751-755, 2001.

BEN-HAMMOUDA, M.; KREMER, R. J.; MINOR, H. C. Phytotoxicity of extracts from sorghum plant components on wheat seedlings. Crop Sci., v. 35, n. 6, p. 1652-1656, 1995a.

BEN-HAMMOUDA, M. et al. A chemical basis for differential allelopathic potential of sorghum hybrids on wheat. J. Chem. Ecol., v. 21, n. 6, p. 775-786, 1995 b.

CHEEMA, Z. A.; KHALIQ, A. Use of sorghum allelopathic properties to control weeds in irrigated wheat in a semi arid region of Punjab. Agric. Ecosy. Environ., v. 79, p. 105-112, 2000 .

EINHELLIG, F. A.; RASMUSSEN, J. A. Prior cropping with grain sorghum inhibits weeds. J. Chem. Ecol., v. 15, n. 3, p. 951-960, 1989 .

HOFFMAN, M. L. et al. Separating the effects of sorghum (Sorghum bicolor) and rye (Secale cereale) root and shoot residues on weed development. Weed Sci., v. 44, p. 402407, 1996a.

HOFFMAN, M. L. et al. Allelopathic influence of germinating seeds and seedlings of cover crops on weed species. Weed Sci., v. 44, p. 579-584, 1996b.
MATEUS, G. P.; CRUSCIOL, C. A. C.; NEGRISOLI, E. Palhada do sorgo de guiné gigante no estabelecimento de plantas daninhas em área de plantio direto. Pesq. Agropec. Bras., v. 39, n. 6, p. 539-542, 2004.

NIMBAL, C. I. et al. Phytotoxicity and distribution of sorgoleone in grain sorghum germplasm. J. Agric. Food Chem., v. 44, p. 1343-1347, 1996.

PEIXOTO, M. F.; SOUZA, I. F. Efeitos de doses de imazamox e densidades de sorgo (Sorghum bicolor (L.) Moench) em soja (Glycine max (L.) Merril) sob plantio direto. Ci. Agrotecnol., v. 26, n. 2, p. 252-258, 2002.

ROTH, C. M.; SHROYER, J. P.; PAULSEN, G. M. Allelopathy of sorghum on wheat under several tillage systems. Agron. J., v. 92, n. 5, p. 855-860, 2000.

SANTOS, O. G. Alelopatia de genótipos de sorgo (Sorghum bicolor) em sistemas de cultivos de hortaliças. 1996. 27 f. Dissertação (Mestrado em Agronomia) Universidade de Brasília, Brasília, 1996.

TREZZI, M. M.; VIDAL, R. A. Potencial de utilização de cobertura vegetal de sorgo e milheto na supressão de plantas daninhas em condição de campo: II- efeitos da cobertura morta. Planta Daninha, v. 22, n. 1, p. 1-10, 2004.

WESTON, L. A.; NIMBAL, C. I.; CZARNOTA, M. A. Activity and persistence of sorgoleone, a long - chain hydroquinone produced by Sorghum bicolor. BRIGHTON CROP PROTECTION CONFERENCE: Weeds, 1997, Brighton. In: Proceedings... Brighton: 1997. v. 2. p. 509-516. 